\title{
Ways of understanding evidence-based practice in social work: A qualitative study
}

\author{
Gunilla Avby, Per Nilsen and Madeleine Abrandt Dahlgren
}

Linköping University Post Print

Tweet

N.B.: When citing this work, cite the original article.

Original Publication:

Gunilla Avby, Per Nilsen and Madeleine Abrandt Dahlgren, Ways of understanding evidencebased practice in social work: A qualitative study, 2014, British Journal of Social Work, (44), 6, 1366-1383.

http://dx.doi.org/10.1093/bjsw/bcs 198

Copyright: Oxford University Press (OUP): Policy E - Oxford Open Option D http://www.oxfordjournals.org/

Postprint available at: Linköping University Electronic Press

http://urn.kb.se/resolve?urn=urn:nbn:se:liu:diva-87398 


\title{
Ways of Understanding Evidence-Based Practice in Social Work: A Qualitative Study
}

\author{
Gunilla Avby
}

Helix Vinn Excellence Centre, Department of Behavioural Sciences and Learning, Linköping

University, SE-581 83 Linköping, Sweden

\section{Per Nilsen}

Department of Medical and Health Sciences, Linköping University, SE-581 83 Linköping,

Sweden

\author{
Madeleine Abrandt-Dahlgren \\ Department of Behavioural Sciences and Learning, Linköping University, SE-581 83 Linköping, \\ Sweden
}

Gunilla Avby has a Master of Arts with a major in Education and a Bachelor in Human Resource Development. She has extended working experience from the adult learning area, especially with a focus on executive training in the public sector. Her research interest lays in workplace learning and she is currently doing Ph.D. research into knowledge use among social workers. Per Nilsen is an associate professor of Community Medicine. His research has focused on health care interventions aimed at achieving health-related behaviour change and he has a particular interest in behaviour change mechanisms. Madeleine Abrandt-Dahlgren is professor in Medical Education. Her main research interest concerns student learning in higher education with a particular view to professional learning in different fields, as well as the relationship between higher education and working life.

Corresponding author's contact details:

Gunilla Avby, Department of Behavioural Sciences and Learning, Linköping University, SE-581 83 Linköping, Sweden. E-mail: gunilla.avby@liu.se

\section{Acknowledgement}

No funding has been received for this study. 


\section{Ways of understanding evidence-based practice in social work: a qualitative study}

\section{Abstract}

This qualitative, empirical study explores and describes the variation in how evidencebased practice (EBP) is understood in social work. A phenomenographic approach to design and analysis was applied. Fourteen semi-structured interviews were conducted with politicians, managers and executive staff in three social welfare offices in Sweden. The main findings suggest that there are qualitatively different ways in which EBP is understood, described in five categories: (i) fragmented; (ii) discursive; (iii) instrumental; (iv) multifaceted; and (v) critical. The outcome space is hierarchically structured with a logical relationship between the categories. However, the informants found it difficult to account for EBP, depending on what was expressed as deficient knowledge of EBP in the organization, as well as ability to provide a seemly context for EBP. The results highlight the importance of acknowledging these differences in the organization to compose a supportive atmosphere for EBP to thrive rather than merely assume the case of evidence-based social work. The categories can be utilized as stimuli for reflection in social work practice, and thereby provide the possibility to promote knowledge use and learning in the evolving evidence-based social work.

Keywords: EBP, evidence-based social work in Sweden, knowledge, learning, phenomenography 


\section{Introduction}

Evidence-based practice (EBP) has become a powerful movement that influences many sectors, from health care to management (Gambrill, 2007). Briefly EBP is about laying down general principles, based on evidence, to reinforce guidance and methods in practice (McCracken and Marsh, 2008). Social work is not left impervious. Gray et al. (2009) declare that EBP is expected to change the content and structure of social work. There are expectations for a practice that is measurable, knowledgeable and utilizes research when determining which methods are most efficient (Soydan, 2010).

Although there is considerable interest in evidence-based social work, there is limited agreement about the definition of EBP and the potential merits of EBP in this field. With roots in evidence-based medicine, the research tradition of social work clashes with the central epistemological, ontological and methodological tenets of EBP, being more oriented towards qualitative and non-experimental social sciences research, in contrast to medical research where the balance is tilted towards quantitative and experimental natural sciences research (Webb, 2001). Advocates of EBP tend to view the process of knowledge application as unproblematic. In contrast, the culture that has long been dominant in social work tends to emphasize learning from practice (Sheppard et al., 2000) and gives an important role to practitioners' experience and judgement. Social work practice is a highly skilled activity that requires a vast knowledge base. Yet, there is a long-standing debate concerning what counts as evidence and valuable knowledge for work in this sector (Trevithick, 2008). With this complex web of knowledge traditions, practices and learning in mind, this article focuses on exploring the ways in which EBP is understood by different stakeholders within social work.

Consistent with international trends, social work in Sweden has come under close scrutiny and many actors, including politicians, policymakers and researchers, have displayed a growing interest in evidence-based approaches to achieve quality improvement and increased efficiency (Tengvald, 2008). Governmental initiatives for more evidence-based social work have been undertaken since the late 1990s based on findings that the existing knowledge base is undeveloped and the effects of different treatment methods do not rely on evidence (Socialdepartementet, 2010). Bergmark et al. (2011) report that social workers and managers in Sweden are generally positive towards EBP, but that local politicians have been more sceptical and have not yet embraced EBP. However, what lies beneath these positive attitudes and actually determines the understanding of EBP is believed to be rather superficial. 
This inconclusiveness concerning EBP has opened the way for social work practitioners to form their own individual interpretation of EBP, suggesting that they will respond to and adopt EBP on the basis of their own understanding (Berger and Luckmann, 1967). This article fills important knowledge gaps given the scarcity of empirical research devoted to different stakeholders' understanding of EBP in social work.

\section{The concept of EBP}

EBP has its origins in evidence-based medicine (Cochrane, 1972) but the concept was not defined until 1992. To clarify the understanding of the concept, Sackett et al. (1996, p. 71) offered the following widely quoted definition: 'the conscientious, explicit, and judicious use of current best evidence in making decisions about the care of individual patients'. Today EBP influences many sectors and has been defined in multiple ways: as a philosophical approach, program, theory, endeavour, meeting, method, process, life-long learning and practical application including empirically validated treatments and guidelines (e.g. Gambrill, 2007; Bohlin and Sager, 2011). There appears to be considerable consensus among researchers that EBP is based on a combination of three different knowledge sources:

- the client's values, preferences and experiences;

- the professional expertise;

- knowledge derived from research (Haynes et al., 2002).

Gray et al. (2009) report that EBP is an emergent phenomenon in social work and describe EBP in terms of 'A specialist research infrastructure that can guide particular interventions, support best practice governance and demonstrate positive outcomes for service users' (p. 1).

A Swedish definition was introduced in 2008 by the Ministry for Health and Social Affairs: 'A practice based on the client's experience, the professional expertise and best available evidence' (SOU, 2008, p. 22). Oscarsson (2009) emphasize that the purpose of creating a practice based on evidence is part of a wider attempt to fortify the quality of social services. The understanding of EBP as part of a welfare system has been highlighted and the definition broadened to include the view of EBP as an approach, which indicates the need to develop a structured learning process at the individual, group and system levels, in which researchbased knowledge is included (Regeringen, 2011). There is a growing emphasis on documentation, measurements and evaluation (SOU 2008, p. 18; IMS, 2008), but also that 
EBP is absent in the laws controlling social work in Sweden; instead quality in services are emphasized (Socialstyrelsen-IMS, 2010).

\section{Knowledge forms and knowledge use}

Empirical-based practice, as well as recent EBP, share a commitment to scientific methods as the best way of determining reliable knowledge (Gray et al., 2009). However, the authors declare that: 'evidence is a form of knowledge. But ... it is just that. Evidence is only one form of knowledge among many' (p. 13). This statement is in line with Lindblom and Cohen's (1979) finding that knowledge has different degrees of verification and arises from different sources. They distinguish between ordinary knowledge and other knowledge sources: 'knowledge is knowledge to anyone who takes it as a basis for some commitment or action.' (p. 12). Ordinary knowledge is seen as knowledge related to thoughtful speculation or commonsense, which is the knowledge shared with others in the normal routines of everyday life (Berger and Luckmann, 1967). It is also known as tacit knowledge (Schön, 1983); the terms clinical expertise (Sackett et al., 1997) and practice-based knowledge (Nilsen et al., 2012) are also used. What Lindblom and Cohen (1979) refer to as other knowledge sources is related to some degree of verification. Other knowledge sources can be addressed as researchbased, explicit or codified knowledge (Nonaka, 1991; 'authors own', 2012). Knowledge is explicit, scientifically grounded and derived from empirical research as well as concepts, theories, models and frameworks (Nilsen et al., 2012).

Many of the controversies and challenges surrounding EBP are rooted in the difficulty in acquiring and balancing knowledge from both practice and theory (Walker, 2007). In practice, it is not obvious where knowledge is drawn from as practice-based and research-based knowledge are intertwined (Nilsen et al., 2012); tacit and explicit knowledge can be seen as mutually complementary entities (Nonaka, 1991). A holistic perspective, which involves an integrated approach when looking at different issues, is apparent in Dewey's (1933) work from the last century. Central in Dewey's concept, 'intelligent action' is the belief that action alone does not create learning, declaring that development (read learning) is derived, in addition to the necessity for a holistic perspective, by reflexive thinking, experience and democracy. It is claimed that one of the main problems hindering development is if contradictory terms or concepts are continuously polarized and never meet. Gould (2004) highlights the importance of recognizing the relationship between formal knowledge and practice, and thereby identifying learning and development in the workplace. Practitioners, 
including social workers, are influenced by formal knowledge, which affects practice. However, by the understanding of 'practice as applied formal knowledge, underestimates the context of practice as a formative influence in knowledge-use and creation' (Gould, 2004, p. 4).

Against the backdrop of the review of previous research and controversies surrounding $\mathrm{EBP}$, it is reasonable to assume that the way in which EBP is understood will have an impact on the extent that the evidence-based practice ideals are incorporated in the everyday practice of social work, and how it is taken up by stakeholders within social work organizations. However, empirical research on practitioners' views on these issues is scarce. The aim of the present study is to reveal how EBP is viewed by people working in social work, and it focuses on what they talk about and how they talk about EBP.

\section{Research methods}

The study takes inspiration from a phenomenographic approach (Marton, 1981). During the 1970s, phenomenography evolved as a methodology to reveal qualitatively different ways of understanding a phenomenon (Dahlgren, 1998). People's understanding of a phenomenon is found in a limited number of qualitatively different ways and from a phenomenographic point of view, the ambition is to reflect these understandings and not judge a statement as something right or wrong (Marton and Booth, 2000). In order to better understand how people deal with problems or situations, phenomenography suggests taking the point of departure as the understanding of the problem or situation to be dealt with.

\section{Study setting}

Swedish social care services, of which social work is a part, is publicly funded and employs approximately 250000 people (SKL, 2012), In comparison with some other welfare states, political power in Sweden is decentralized, with extensive authority given to 290 municipalities, also known as municipal councils. Each municipality has an elected council that has powers over most matters of local administration and acts as frontline agency in social care delivery (Soydan, 2010).

The primary law governing social care is a goal-oriented enabling act (Social Services Act) based on voluntary efforts. The legal framework allows considerable freedom in combination with extensive trust, which calls for a great deal of professional autonomy and authority to act 
independently. It also requires broad competence to work over a wide field. The often very complex matters handled in social care require widespread cooperation with other actors in the local area; for example, school, police, psychologist, health care and migration. It is impossible to provide an overall description of social services, as there are local differences in the organization and delivery of welfare services.

\section{Study design}

The study recruited people from three levels: political, managerial and executive staff. Study participants came from three Swedish municipality welfare offices of different sizes. One municipality is considered to be a metropolitan area with much of what is associated with major cities with a population of 150 000. The other two municipalities have a population of 42000 and 25 000, respectively. The three municipalities were chosen due to their engagement in an on-going research project targeting families in socially and economically vulnerable situations.

Fourteen interviews were conducted with six females and eight males during the autumn of 2011. The interviewees who belonged to the managerial (six persons) and staff (three persons) levels had an average of twenty-five years of working experience in the social service sector, ranging from one to thirty-nine years; the politicians (five persons) had served half these years. The length of time in present positions varied from one to twelve years; staff had served the most years and politicians the least. The respondents were between thirty-five and sixty-one years of age. All the managers and staff personnel had a university degree, whereas none of the politicians did (Figure 1).

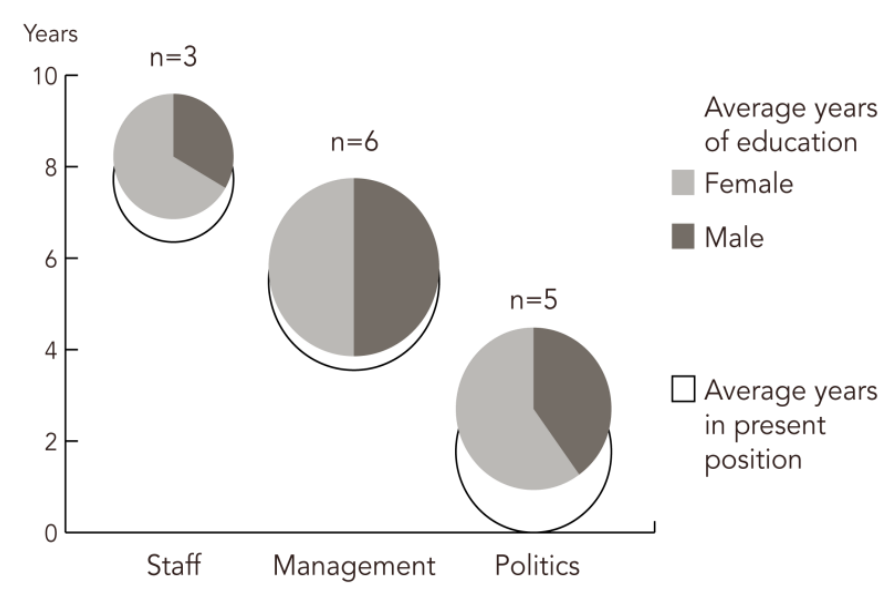


Figure 1. Background data.

Data were collected via semi-structured interviews. Each interview took approximately forty-five to sixty minutes. All interviews were in Swedish, and were recorded and later transcribed verbatim. The original statements included in this article have been translated by the leading author. Some details are adapted for written text in order to facilitate reading.

All interviews were conducted by the same interviewer and an interview guide was used to enhance dependability. The interview guide was piloted with two social workers, which were not included in the main study. In order to reach the individual's unreflected experiences (Marton and Booth, 2000), no explicit definition of EBP was provided. After introductions were made, the phenomenographic introductory question was 'What is EBP for you?', whereby the respondents freely associated with the phenomenon. To deepen understanding of the respondent's ways of understanding the phenomenon, abstract and decontextualized questions were combined with encouragements to describe the phenomenon through direct experiences and visualizing the consequences, referred to as 'situated examples' (Åkerlind, 2005, p. 106). To verify that the respondents' descriptions were interpreted correctly, summarizing of statements took place during the interviews. Credibility was the aim by using illustrative quotes from the data collected when presenting the results (Alexandersson, 1994).

\section{Ethical considerations}

Permission to carry out the study was given by the steering committee for the existing research project in the regional government. The committee was attended by participants from the three chosen municipalities. Verbal consent was obtained from the fourteen participants, including assurances of confidentiality.

\section{Analysis}

A phenomenographic analysis procedure was performed in accordance with the seven steps described by Dahlgren and Fallsberg (1991):

Step 1: Familiarization. The first step was to read through the transcripts in their entirety to gain a sense of the whole.

Step 2: Consolidation. While listening to the interviews, interesting passages responding to the research questions were marked and recorded in a table. 
Step 3: Comparison. The accounts were re-read and compared with the data excerpts collected in search of similarities and differences. Different aspects of the phenomenon emerged, which represented different individual ways to describe the phenomenon.

Step 4: Grouping. A search began to reveal a pattern that could illustrate the data excerpts collected. Data excerpts that indicated similarities were grouped together resulting in different empirically based categories. When new understandings appeared, the transcripts were once again consulted, which resulted in reconsidering and regrouping the understandings several times until saturation in the analysis was reached.

Step 5: Articulation. The analysis continued by focusing on how the aspects delimited in Step 3 were perceived and related internally. The process resulted in five descriptive categories symbolizing separate ways to understand EBP on a collective level, with a limited and central content for each category.

Step 6: Labelling. A name was given to each denoted category.

Step 7: Contrasting. The analysis concluded by investigating internal relationships across the categories and revealing possible hierarchical relations between them. This constituted the outcome space. In the construction of an outcome space, individual aspects expressed are contrasted with one another to depict the relationship between the categories. In Step 5 the aspects were related internally, which resulted in different categories. In this final step, the aspects were contrasted in a search for possible relations between all the aspects of EBP that were described.

\section{Results}

The analysis yielded five qualitative different understandings of EBP based on the relationship between three delimited aspects: (i) how respondents believed EBP has influenced regular social work practice; (ii) their perception of quality in social work practice in relation to EBP, and (iii) their views of knowledge (including what counts as important knowledge in social work, how knowledge is produced, how evidence and knowledge are related). These five ways of understanding EBP resulted in five main categories:
(1) Fragmented
(2) Discursive
(3) Instrumental 


\section{(4) Multifaceted}

\section{(5) Critical}

The five categories form a hierarchy with an internal relationship so that understanding at one level encompasses understandings at lower levels. Thus, understanding (3) is more comprehensive than (2), and understanding (4) is more comprehensive than (2) and (3) together, whereas understanding (5) implies traces of understanding (2) to (4). The fragmented understanding (1) falls outside this logical relationship caused by the understanding's imprecision in targeting the immediate phenomenon. Nevertheless, it is an understanding (or non-understanding) of EBP and is therefore part of the hierarchical outcome space as illustrated in Figure 2. It is possible for a respondent to appear in more than one category based on various statements in their account. For each category, a representative quote was selected. The number following the quote is connected to one of the fourteen respondents.

\begin{tabular}{|c|c|c|c|c|c|}
\hline \multirow{6}{*}{ 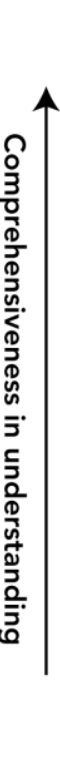 } & & & $\begin{array}{l}\text { Description } \\
\text { of practice }\end{array}$ & $\begin{array}{l}\text { Perception } \\
\text { of quality }\end{array}$ & $\begin{array}{l}\text { View } \\
\text { of knowledge }\end{array}$ \\
\hline & v & Critical & $\begin{array}{l}\text { Reflective practice } \\
\text { Challenging }\end{array}$ & $\begin{array}{l}\text { Justice } \\
\text { Awareness }\end{array}$ & $\begin{array}{l}\text { Appraised } \\
\text { Contextualized }\end{array}$ \\
\hline & iv & Multifaceted & $\begin{array}{l}\text { Informed practice } \\
\text { Knowledgeable }\end{array}$ & $\begin{array}{l}\text { Cliental empowerment } \\
\text { Accountability } \\
\text { Transparency }\end{array}$ & $\begin{array}{l}\text { Integrated } \\
\text { Explicit and implicit }\end{array}$ \\
\hline & $\mathrm{iii}$ & Instrumental & $\begin{array}{l}\text { Guided practice } \\
\text { Developmental }\end{array}$ & $\begin{array}{l}\text { Reliable } \\
\text { Manageable } \\
\text { Continuous } \\
\text { improvements }\end{array}$ & $\begin{array}{l}\text { Research-based } \\
\text { Explicit }\end{array}$ \\
\hline & ii & Discursive & $\begin{array}{l}\text { Up-to-date practice } \\
\text { Modern }\end{array}$ & $\begin{array}{l}\text { Legitimizing } \\
\text { Manifested in policy }\end{array}$ & $\begin{array}{l}\text { Practice-based } \\
\text { Implicit }\end{array}$ \\
\hline & i & Fragmented & Traditional & - & - \\
\hline
\end{tabular}

Figure 2. Outcome space. The five ways of understanding EBP constitute a hierarchical structure. Descriptions pertaining to the three aspects are shown at each level of understanding. 


\section{Fragmented}

In this first category, the understanding of EBP is vague or largely lacking. There appears to be no relationship between respondents' description of practice and perception of quality and knowledge, which causes a fragmented understanding of EBP. Statements establish EBP as an occurrence figuring in practice, but without formulating an actual content. Rather than attempting to explain how EBP is understood, respondents suggest it is interchangeable with the term 'quality':

I don't have a good answer of what EBP is. Knowledge is involved somehow. I can't say that we politicians know much about it. It could be an approach. I really don't know (R7 and R11).

\section{Discursive}

How EBP is understood in the second category resembles the vagueness expressed in the first category, but, in contrast, an individual interpretation is expressed to be necessary and thereafter applied. Respondents talk about EBP as an abstract concept causing confusion rather than acknowledging support for practice formation. EBP is nevertheless announced as an important concept in social work in order to legitimize work and embrace prevailing discourse. EBP is predominantly associated with a sort of quality assurance that signifies that practice is modern and keeping up with the changes in the field, particularly if EBP is articulated in documents and various situations. However, they did not talk about EBP in terms of social work being more underpinned by research-based knowledge than previously. Instead, they emphasized the importance of experience and the use of practice-based knowledge to become a skilled social worker:

EBP has arrived as, maybe not a saviour, but as something that might legitimatize what we do. Everyone talks about evidence and evidence-based like some kind of religious belief on a shallow level. It has appeared on the agenda and on a scientific level certain methods are being assured. I don't have a deeper knowledge of what evidence-based methods are if someone doesn't inform me. People have talked about EBP for a decade, but I haven't seen any results of it as nobody ties it together. It is a utopia. I talk about evidence because it has become politically correct. Our business plan includes statistics of the usage of evidence-based methods (R3).

\section{Instrumental}

A prominent feature in the third category is the respondents' expressions of EBP in rather instrumental terms, i.e. EBP is seen as the implementation of and adherence to scientifically 
based methods and routines in social work practice. The respondents view quality assurance and continuous improvement of social work practice as key rationale for implementing EBP. They also emphasize the importance of achieving more standardized social work practices and reduction in practice differences. EBP is associated with documentation, evaluation and using protocols for social work practice. They are in favour of applying methods of proven effectiveness based on experimentally oriented research investigating what works? Valued knowledge is connected to a certain method or treatment, preferably accredited through governmental procedures, although the competence to use the instruments and the relational aspect of social work is acknowledged. With these systematized processes, practice is becoming more reliable and easier to manage. EBP is a basis for higher quality and can account for lack of competence in individuals:

EBP is the use of well-tested methods, proven to work, not necessarily through research, but based on some kind of systematized evaluation. Things are done in the same way, guided by an explicit model, for me, it provides some kind of quality assurance. Still, quality and evidence isn't quite the same, evidence has a higher credibility than quality. The quality of social workers vary and the systematized process gives them something to lean on and makes life so much easier for politicians and decision makers. My experience is that the quality in work has increased. We are replacing treatments with evidence-based methods. However, a problem when implementing new methods coming from the government is the rigidity that doesn't allow even the slightest changes. Evidence and knowledge might be the same thing, but I believe there are higher requirements when talking about evidence (R1).

\section{Multifaceted}

The narratives in the fourth category express key issues such as greater transparency, an expanded knowledge base and engaged actors. It was expressed that traditional social work, which has long been dominated by personal assumptions and social worker's professional autonomy, differs from EBP in how knowledge and information is sought. Knowledge is perceived as accredited through diverse sources, whereas the client is recognized as having a more salient role than ever. Empowerment of clients' autonomy is an important quality aspect within this category. Also, the narratives in this category expressed that the external pressure of accountability is stronger than ever before as practice is highly regulated and inspected by external parties. EBP is considered to be a practice enhanced by information, with bettergrounded arguments:

EBP looks more closely at the client's experience, which has a greater influence on work. EBP is not the same as the social work carried out throughout the years where the professionals autonomously decided 
what and how to do things, working only from their own experience and different trends. It is about lifting our experience to new levels in attempt to develop new knowledge and making it useful to others (R5).

\section{Critical}

Understanding of EBP in this category is characterized by the respondents' ability to discuss and reflect on the complexity of the concept. They identify numerous advantages and disadvantages of implementing EBP in social work, but are able to balance different viewpoints against each other. Some respondents discuss EBP in terms of its potential importance for scrutinizing social work, which they feel might be inconvenient for people who want to avoid changing their work practices. Various knowledge sources are acknowledged as integral to a more evidence-based social work practice and a contextualized view of knowledge is expressed. The view of what counts as evidence is generally broad, encompassing qualitative studies and case studies. Soft research is valued as much as hard quantitative research intended to demonstrate 'does it work?' Respondents highlight the importance of reflection and careful analysis to synthesize various types of knowledge:

\footnotetext{
EBP is to look at what we do and how we do it. It's not just a method, it's about integrating all information and knowledge we have concerning an individual, in combination with the context in which the individual is situated, weighing in influences from other parties, but also considering the context in which we figure. It's about the courage to actually look at the work being done and what is achieved. Many find this discomforting. In order to 'reach' EBP we must accumulate our efforts and make them explicit. Otherwise each and every experience may be 'evidence'. It is incredibly important to use the same language in developing EBP, throughout the organization and when structuring work we need to find space for reflection and consider organizational prerequisites for EBP. We still have trouble finding time for reflection, even though I find that our awareness and self-esteem has progressed (R4).
}

\section{Discussion}

This study sought to explore ways of understanding EBP in social work practice based on interviews with personnel in three social welfare offices in Sweden. Overall, the findings demonstrate that there is a broad range of understanding of EBP in social work, suggesting that the concept has many facets.

The results show that the view of knowledge varied depending on the particular understanding of EBP. A multifaceted and critical understanding of EBP was associated with valuing a range of knowledge forms, both explicit and implicit. This view of knowledge is consistent with the origins of evidence-based medicine, which emphasize the need for both 
guidance and critical appraisal in practice (Sackett, 1996). Early advocates of EBP argued that external evidence can inform, but never replace the professional expertise; ultimately, it is the expert who decides whether or not the evidence is applicable. Practitioners often operate in unpredictable conditions, which highlight the importance of experience derived from practice as a reliable knowledge source (Schön, 1983). However, practitioners need to recognize the ways in which both theory and practice-based knowledge are requested, to exercise 'wise judgement under conditions of uncertainty' (Taylor and White, 2006, p. 937). As Dewey (1933) proclaims, theoretically, knowledge and practice-based experience are the making of each other, and therefore neither one can be valued higher than the other. Instead, these different sources from which knowledge is evoked interact with each other in the creative activities of human beings. In relation to the study's more comprehensive understandings of $\mathrm{EBP}$, the valuing of many knowledge forms was described as having widespread implications: affecting organizational structures, requiring new competencies and continuous knowledge development, i.e. by re-organizing work to create space for reflection and integrating clients early in the process. The implications require a high level of activity and engagement of the organizational members. In contrast to the implications, discursive understanding is achieved by articulating the concept of EBP in organizational administration. An instrumental understanding of EBP is associated with a belief in explicit knowledge, manifested foremost in accredited tools, such as different assessment procedures or manuals approved by authorities.

We found that different understandings of EBP were associated with different descriptions of social work practice. An instrumental understanding was associated with rationality and belief that there is an optimal behaviour that can be achieved in a systematically organized environment. Previous research on EBP in social work has described this approach in terms of a rational choice model (Van de Luitgaarden, 2009; Broadhurst et al., 2010), where the increasingly formal structure for work performance and decision making is conceived to generate knowledge independent of individual human assessment (Bohlin and Sager, 2011). Webb (2001) has argued that a rational choice model is unsatisfactory for social work because the separation of facts and values inherent in this model undermines professional judgement and rules out the subjective dimension needed to interpret human actors' experience. This contradictory view of a challenging and continuously reflecting practice is apparent in the critical understanding of EBP, which harmonizes well with the emphasis on critical appraisal in the original, more philosophical approach to evidence-based medicine (Sackett, 1996). The 
multifaceted understanding suggests a practice that is highly informed and contributes to a public scrutiny of professional authority far removed from the rational positivist approach, but not fully exhibiting the appraisal characteristic. This multifaceted way of understanding EBP can be considered close to what others have entitled evidence-informed practice (Nutley et al., 2003).

The results also show that the perception of quality varied with the different understandings of EBP. Unsurprisingly, the respondents perceived a strong link between quality and EBP. This association can partly be explained by the law governing social care, which stipulates that good quality must be ascertained in social work treatment and care (Socialdepartementet, 2001, p. 453). The quality-EBP link can also be explained with reference to EBP's origins in new forms of governance and extended trust in a scientific society, where great efforts are made to guarantee that each and every process is based on trustworthy knowledge (Hasselbladh, 2008). The results suggest that the meaning of good quality depends on the understanding of EBP. A discursive understanding implies that the role of quality is first and foremost to legitimize work and act merely as a quality mark. The more comprehensive understandings of EBP were associated with broader and fuller descriptions of quality. In the critical understanding, quality was expressed as awareness of scrutinizing work and justifying work to the benefit of clients.

Opportunities for critical reflection in organizations is a growing necessity (Baldwin, 2004), and the need for cognitive abilities is especially accentuated for the conduct of social work practice (Sheppard, 1998). If analytical reasoning is non-existent in social work, tacit knowledge will become a cognitive prison hindering social workers' utilization of a broader knowledge base in practice (Nordlander, 2006). Also, emotion and interpretation are seen as important features in social work (Taylor and White, 2006). Delineated route would suggest that the critical and multi-faceted understandings identified in this study will be needed. In parallel, the increasing complexity and unpredictability in organizations puts a stronger emphasis on modern organizational development and managerial control (Hasselbladh, 2008), which would suggest the need for the instrumental understanding to advance. However, considering the ambiguous and vague understanding of EBP in the organizations, EBP might not prosper at all, or evolve in another or simultaneously different direction.

In Sweden, EBP is often applied in the sense of evidence-based interventions (Soydan, 2010, p. 187), albeit with practitioners' limited knowledge of what counts as evidence-based 
methods and assessments (Socialstyrelsen, 2011). Thus far, EBP in social work in Sweden has adhered most closely to a rational model (e.g. Broadhurst, et al., 2010), namely resembling the instrumental understanding as described in this study. This rational approach to and understanding of EBP is evident in a recent government-supported survey conducted among a representative sample of managers in social services agencies, which observed that the dissemination of evidence-based methods and assessments are a prerequisite for EBP (Socialstyrelsen, 2011). This view of EBP, as primarily involving the implementation of evidence-based methods and assessments in practice, suggests that the critical understanding of EBP that is needed to achieve a reflective practice is a long way off in Swedish social work.

What are the implications of the findings of this study? In agreement with previous research, the findings clearly underline the difficulty of accounting for EBP in practice (Gray et al., 2009). Our findings suggest that adherence to EBP has not yet been realized in social work. The results thus support the observations of some of the leading spokesmen in social work in Sweden, who maintain that EBP remains a vision rather than a reality (Bergmark, et al., 2011): '... policy tends to drive practice in Sweden rather than vice versa, and the demand for EBP was not professionally driven in its initial stages' (Soydan, 2010). Thus, EBP has not been implemented as something uniform, which opens the way for individual interpretation, from very narrow understandings to broader, more all-encompassing understanding. The findings indicate that the conceptual language, signifying how EBP is talked about, is vague, unsatisfactory and largely divergent. It causes difficulties in the formation of an abstract conceptual language for social work, which is a basis for knowledge use and creation (e.g. Gould, 2004). Even though the lack of agreement and consistency in relation to terminology is confusing and causes difficulties for social workers in articulating what they know, Trevithick (2008) claims that 'it serves as a reminder of the limited priority given to defining key concepts commonly used in social work' (p. 1221). The clarity in her statement implies support for this study's focus on exploring practitioners' understanding of EBP.

How can EBP fulfil the contrasting needs and comprise both critical reflection and managerial control in today's organizations? Further empirical research in actual practical settings is needed to provide a better understanding of EBP as a working practice promoting the integration of different knowledge sources. The knowledge-development potential of practitioners in social work is not fully exploited and if not considered, with EBP follows the 
risk that practice is portrayed as the poor relative of research, viewed as a passive recipient of knowledge created elsewhere (March and Fisher, 2008).

This study has certain limitations that must be considered when interpreting the results. Based on interviews, the study aimed at revealing how EBP is characterized in social work in Sweden. The material from an interview is not a one and only truth; instead it is highly dependent on chosen perspectives. A phenomenographic approach was chosen, with the purpose of identifying different understandings of the phenomenon in focus (Marton, 1981), to reveal various aspects of EBP in social work, rather than seeking to explain mechanics causing a certain understanding. The study was carried out on a relatively small group of 14 people, but this is in line with recommendations that 10-15 interview transcripts are an ideal number to analyze at one time (Åkerlind, 2005). The study was conducted with managers and other stakeholders in social work offices in three municipalities in Sweden. The social work offices and municipalities selected are largely representative and symbolize a normal regional government. The respondents were chosen on the basis of the positions they hold as important stakeholders and decision makers in the chosen municipalities with relevance to service delivery in social work. This suggests that similar understandings would likely be found in other social work settings, at least those consisting of stakeholders and decision makers in Swedish social work, but probably with slightly different emphases. Notwithstanding the study aim of identifying qualitatively different ways of understanding EBP, rather than comparing different categories of interviewees, we need to address whether the results can be usefully analysed by type of interviewee. However, the analysis did not indicate patterns between the categories of people associated with their position. Instead the individuals' work experience appeared to be an important variable which affected their understanding.

\section{Conclusion}

In conclusion, this article has pointed to the importance of acknowledging the different ways in which EBP is understood to compose a supportive atmosphere for EBP to thrive and to realize a social work practice that utilizes various knowledge sources, both research-based knowledge and practice-based knowledge to the benefit of clients. Using a phenomenographic approach, a taxonomy of five descriptive categories (fragmented, discursive, instrumental, multifaceted and critical) were identified and they portray different ways of understanding EBP in social work. The inconclusiveness related to EBP implies different routes for EBP in social work depending on which understanding is most influential. 
Ultimately, the results of this study provides means of understanding EBP in social work and offer a way of making practitioners and decision makers in social work aware of different ways of understanding key elements of EBP, from a fragmented understanding to a critical understanding.

\section{References}

Åkerlind, G. (2005) 'Phenomenographic methods: a case illustration', in Green, J. A. B. P. (ed), Doing Developmental Phenomenography, Melbourne, RMIT University Press.

Alexandersson, M. (1994) 'Den fenomenografiska forskningsansatsens fokus [The phenomenographic approach]', in Bengt Starrin, B. and Svensson, P.-G. (eds), Kvalitativ metod och vetenskapsteori [Qualitative Methodology and Philosophy of Science], Vol. 1, Lund, Studentlitteratur, p. 20 (in Swedish).

Baldwin, M. (2004) 'Critical reflection: opportunities and threats to professional learning and service development in social work organizations', Gould, N. and Baldwin, M. (eds), Social Work, Critical Reflection and the Learning Organization, Aldershot, Ashgate Publishing.

Berger, P. and Luckmann, T. (1967) The Social Construction of Reality, New York, Anchor Books.

Bergmark, A., Bergmark, A. and Lundström, T. (2011) Evidensbaserat socialt arbete. Teori, kritik, praktik [Evidence-based social work. Theory, critism, practice], Stockholm: Natur \& Kultur (in Swedish).

Bohlin, I. and Sager, M. (2011) Evidensens många ansikten: evidensbaserad praktik $i$ praktiken [The Many Faces of Evidence: Evidence-based Practice in Practice], Lund, Arkiv.

Broadhurst, K., Hall, C., Wastell, D., White, S. and Pithouse, A. (2010) 'Risk, instrumentalism and the humane project in social work: identifying the informal logics of risk management in children's statutory services', British Journal of Social Work, 40(4), pp. 1046-1064. 
Cochrane, Archibald. (1972). 'Effectiveness and efficiency: random reflections on health services', London, Nuffield Provincial Hospitals Trust.

Dahlgren, L.-O. and Fallsberg, M. (1991) 'Phenomenography as a qualitative approach in social pharmacy 'esearch', Journal of Social and Administrative Pharmacy, 8, pp. $150-156$.

Dahlgren, M. A. (1998) 'Learning physiotherapy: Students' ways of experienceing the patient encounter', Physiotherapy Research International, 3(4), pp. 257-73.

Dewey, J. (1933) How we think. A Restatement of the Relation of Reflective Thinking in the Educative Process, Boston, MA, Heath.

Gambrill, E. (2007) 'Views of evidence-based practice: social workers' code of ethics and accreditation standards as guides for choice', Journal of Social Work Education, 43(3), pp. 447-462.

Gould, N. (2004) 'Introduction: the learning organization and reflective practice - the emergence of a concept', in Gould, N. and Baldwin, M. (eds), Social Work, Critical Reflection and the Learning Organization, Aldershot, Ashgate Publishing.

Gray, M., Plath, D. and Webb, S. A. (2009) Evidence-based Social Work. A Critical Stance, London, Routledge.

Hasselbladh, H., Bejerot, E. and Gustafsson, R. Å. (2008) Bortom New Public Management: institutionell transformation i svensk sjukvård [Beyond the New Public Management: Institutional Transformation in Swedish Health Care], Lund, Academia Adacta (in Swedish).

Haynes, B., Devereaux, P. and Gordon, G. (2002) 'Physicians' and patients' choices in evidence based practice: evidence does not make decisions, people do', $B M J$, 324(7350), p. 1350.

Lindblom, C. E. and Cohen, D. K. (1979) Usable Knowledge, New Haven, CT: Yale University.

Marsh, P. and Fisher, M. (2008) 'The development of problem-solving knowledge for social care practice', British Journal of Social Work, 38, pp. 971-987. 
Marton, F. (1981) 'Phenomenography — describing conceptions of the world around us', Instructional Science, 10(2), pp. 177-200, doi:10.1007/bf00132516

Marton, F. and Booth, S. (2000) Om lärande [Learning and Awareness], Lund, Studentlitteratur (in Swedish).

McCracken, S. G. and Marsh, J. C. (2008) 'Practitioner expertise in evidence-based practice decision making', Research on Social Work Practice, 18(4), pp. 301-310, doi:10.1177/1049731507308143

Nilsen, P. and Ellström, P.-E. (2012) 'Fostering practice-based innovation through reflection at work', in H. Melkas and V. Harmaakorpi (eds), Practice-Based Innovation: Insights, Applications and Policy Implications, Berlin, Springer.

Nilsen, p., Nordström, G. and Ellström, P.-E. (2012) 'Integrating research-based and practicebased knowledge through workplace reflection', Journal of Workplace Learing, 24(6), pp. 403-15.

Nonaka, I. (1991) ‘The knowledge creating company', Harvard Business Review, 69(NovDec), pp. 96-104.

Nordlander, L. (2006) 'Mellan kunskap och handling - Om socialsekreterares kunskapsanvändning i utredningsarbetet', Doctoral thesis, Umeå University, Umeå.

Nutley, S., Walter, I. and Davies, H. T. O. (2003) 'From knowing to doing', Evaluation, 9(2), pp. 125-148, doi:10.1177/1356389003009002002

Oscarsson, L. (2009) Evidensbaserad praktik inom socialtjänsten: en introduktion för praktiker, chefer, politiker och studenter [Evidence-based Practice in Social Services: An Introduction for Practitioners, Managers, Politicians and Students], Stockholm, SKL Kommentus (in Swedish).

Regeringen (2011) Överenskommelse om stöd till en evidensbaserad praktik inom socialtjänstens område [Agreement on Support for Evidence-based Practice in the field of Social Services], Stockholm, Socialdepartementet.

Sackett, D. L. (1996) 'Evidence based medicine: what it is and what it isn't', BMJ, 312(7023), pp. 71-72. 
Schön, D. A. (1983) The Reflective Practitioner - How Professinals Think in Action, London, Basic Books.

Sheppard, M. (1998) 'Practice validity, reflexivity and knowledge for social work', British Journal of Social Work, 28(5), pp. 763-781.

Sheppard, M., Newstead, S., Di Caccavo, A. and Ryan, K. (2000) 'Reflexivity and the development of process knowledge in social work: a classification and empirical study', British Journal of Social Work, 30(4), pp. 465-488, doi:10.1093/bjsw/30.4.465

SKL (2012) Sveriges kommuner och landsting [Swedish Association of Local Authorities and Regions], available online at www.skl.se/kommuner_och_landsting/antal-anstalldaper-personalgrupp.

Socialdepartementet (2001) Socialtjänstlag SFS (2001:413) [Social Services Act (2001:413)], available online at www.riksdagen.se /sv /Dokument-Lagar/Lagar/ Svenskfofattningssamling/Socialtjanstlag-2001453_sfs-2001-453/?bet=2001:453.

Socialdepartementet (2010) Plattform för arbetet med att utveckla en evidensbaserad praktik $i$ socialtjänst [Platform for the Work to Develop Evidence-based Practice in Social Services], Stockholm (in Swedish).

Socialstyrelsen-IMS (2010) Att leda evidensbaserad praktik - en guide för dig som är chef inom socialt arbete [Leading Evidence-based Practice - A Guide for Social Work Managers], Västerås, Edita Västra Aros AB (in Swedish).

Socialstyrelsen (2011) Evidensbaserad praktik i socialtjänsten 2007 och 2010 [Evidencebased Practice in Social Services in 2007 and 2010], Socialstyrelsen (in Swedish).

SOU (2008) Evidensbaserad praktik inom socialtjänsten - till nytta för brukaren: betänkande av utredningen för en kunskapsbaserad socialtjänst [Evidence-based Practice in Social Services - To the Benefit of the Patient: Report of an Investigation on Knowledge-based Social Services], Stockholm, Fritzes (in Swedish).

Soydan, H. (2010) 'Evidence and policy: the case of social care services in Sweden', The Policy Press, 6(2), pp. 179-193. 
Taylor, C. and White, S. (2006) 'Knowledge and reasoning in social work: educating for humane judgement', British Journal of Social Work, 36(6), pp. 937-954, doi:10.1093/bjsw/bch365

Tengvald, K. (2008) 'Den evidensbaserade praktiken i sitt sammanhang', in U. Jergeby (Ed.), Evidensbaserad praktik i socialt arbete [Evidence-based Practice in Social Work], Stockholm, Gothia/IMS.

Trevithick, P. (2008) 'Revisiting the knowledge base of social work: a framework for practice', British Journal of Social Work, 38(6), pp. 1212-1237, doi:10.1093/bjsw/bcm026

Walker, J. S. (2007) 'Implementing and sustaining evidence-based practice in social work', Journal of Social Work Education, 43(3), pp. 361-375.

Van de Luitgaarden, G. M. J. (2009) 'Evidence-based practice in social work: lessons from judgment and decision-making theory', British Journal of Social Work, 39, pp. 234260.

Webb, S. (2001) 'Some considerations on the validity of evidence-based practice in social work', British Journal of Social Work, 31(1), pp. 57-79, doi: 10.1093/bjsw/31.1.57 